\title{
Development of a Downscaling Method in China Regional Summer Precipitation Prediction*
}

\author{
GU Weizong ${ }^{1,2,3,4}$ (顾伟宗), CHEN Lijuan ${ }^{3 \dagger}$ (陈丽娟), LI Weijing ${ }^{3}$ (李维京), and CHEN Deliang ${ }^{5}$ (陈德亮) \\ 1 Chinese Academy of Meteorological Sciences, Beijing 100081, China \\ 2 Nanjing University of Information Science \& Technology, Nanjing 210044, China \\ 3 Laboratory for Climate Studies, National Climate Center, China Meteorological \\ Administration, Beijing 100081, China \\ 4 Shandong Climate Center, Jinan 250031, China \\ 5 Department of Earth Sciences, University of Gothenburg, Göteborg 40530, Sweden
}

(Received July 26, 2010; in final form March 29, 2011)

\begin{abstract}
A downscaling method taking into account of precipitation regionalization is developed and used in the regional summer precipitation prediction (RSPP) in China. The downscaling is realized by utilizing the optimal subset regression based on the hindcast data of the Coupled Ocean-Atmosphere General Climate Model of National Climate Center (CGCM/NCC), the historical reanalysis data, and the observations. The data are detrended in order to remove the influence of the interannual variations on the selection of predictors for the RSPP. Optimal predictors are selected through calculation of anomaly correlation coefficients (ACCs) twice to ensure that the high-skill areas of the CGCM/NCC are also those of observations, with the ACC value reaching the 0.05 significant level. One-year out cross-validation and independent sample tests indicate that the downscaling method is applicable in the prediction of summer precipitation anomaly across most of China with high and stable accuracy, and is much better than the direct CGCM/NCC prediction. The predictors used in the downscaling method for the RSPP are independent and have strong physical meanings, thus leading to the improvements in the prediction of regional precipitation anomalies.

Key words: Coupled Ocean-Atmosphere General Climate Model (CGCM), downscaling method, regional precipitation, prediction

Citation: Gu Weizong, Chen Lijuan, Li Weijing, et al., 2011: Development of a downscaling method in China regional summer precipitation prediction. Acta Meteor. Sinica, 25(3), 303-315, doi: 10.1007/s13351-011-0306-2.
\end{abstract}

\section{Introduction}

Monthly to seasonal climate prediction has been a focus in climate research and is also important for flood and drought prevention. For decades, scientists at home and abroad have done much work to improve the accuracy of monthly to seasonal climate prediction. The downscaling method based on optimized information extracted from climate models has proved to be very effective (Fuentes and Heimann, 1996; Wilby and Wigley, 1997; Li and Chen, 1999; Chen, 2000;
Chen Lijuan et al., 2003; Goddard et al., 2001; Chen and Chen, 2003; Hellstrøm and Chen, 2003; Zhang et al., 2005; Ai et al., 2008; Gu et al., 2009).

China is a vast country with large zonal and meridional spans as well as complex terrains and a great diversity of vegetation. This results in different and complex regional climate features. Based on divisions of appropriate climate regimes and taking the regional climate features as predictands, we can obtain associated large-scale predictors and improve the predictability of regional climate. Many researchers

\footnotetext{
* Supported by the National Science and Technology Support Program of China (2007BAC29B04 and 2009BAC51B05) and Special Public Welfare Research Fund for Meteorological Profession of China Meteorological Adminstration (GYHY200906015).

†Corresponding author: chenlj@cma.gov.cn.

(Chinese version to be published)

(C)The Chinese Meteorological Society and Springer-Verlag Berlin Heidelberg 2011
} 
have studied the climate regionalization of China (Chen and Wu, 1994; Wang et al., 1998; Sun et al., 2005; Ren et al., 2006; Qin and Qian 2006; Chen et al., 2009). Chen et al. (2009) divided China into 13 precipitation regions with the rotated empirical orthogonal function (REOF) applied to the monthly precipitation data from 400 monitoring stations that spread uniformly over China. The precipitation regimes well reflect the regional climate features across China. They are helpful for finding the predictors affecting climates of different regions.

Traditional short-range climate prediction relies mainly on statistical methods to search for predictors and establish prediction equations. The predictors selected this way are only statistical, and no physical relationships between predictors and predictands are embedded, so the prediction skills of this type of methods are not stable. In recent decades, many dynamic climate models have been developed, but their prediction accuracy for seasonal precipitation is not high enough due to the models' defects and systematic errors, thus they cannot meet the demands of routine operations and services. It is urgent to extract and take advantage of optimal information from plenty of dynamic model outputs. The downscaling approach combines dynamic and statistic methods and may thus improve the accuracy of seasonal climate prediction.

The first-generation Coupled Ocean-Atmosphere General Climate Model of National Climate Center (CGCM/NCC) of China, which was formally put into operation in 2005, has offered large amounts of data for the seasonal climate prediction and the related services (Ding et al., 2004; Li et al., 2004; Li et al., 2005). However, direct model outputs of precipitation and temperature still bear a low prediction skill (Chen, 2008). Nonetheless, it is important to explore optimal information from the model outputs and use the regionalized prediction method to improve the seasonal forecast accuracy. In this paper, we take the regional precipitation anomaly as predictands and establish a downscaling method to do the regional summer precipitation prediction (RSPP) in China. Optimal Subset Regression (OSR) is used as transfer function in the
RSPP. On the basis of the regionalized precipitation regimes in China (Chen et al., 2009), hindcast data of the CGCM/NCC and observation data are used to make RSPP with optimized information extracted from the CGCM/NCC. Furthermore, the results of RSPP are compared with the outputs of CGCM/NCC, and the causes of high skill predictions of RSPP are analyzed.

\section{Data}

The data used in this study include monthly precipitation from 400 monitoring stations (Fig. 1) of the National Meteorological Information Centre (NMIC), China Meteorological Administration (CMA), the NCEP/NCAR reanalysis monthly data during the period 1983-2006 (Kalney et al., 1996), and the ensemble average summer atmospheric circulation data produced by the $\mathrm{CGCM} / \mathrm{NCC}$, which is initialized in February. The NCEP/NCAR reanalysis data and the CGCM/NCC output data contain the geopotential height fields at 200 and $500 \mathrm{hPa}$, and the zonal and meridional wind fields at 200 and $850 \mathrm{hPa}$, sharing the same resolution of $2.5^{\circ} \times 2.5^{\circ}$.

\section{Precipitation regionalization}

China regionalized precipitation regimes (Chen et al., 2009) are shown in Fig. 1 with the following characteristics. 1) The regionalization in the central and western parts of China is rather detailed and complete due to the use of the uniformly distributed 400-station data. 2) The regional boundaries are indentified according to the rule of regularity and convenience. 3) The precipitation regimes in the south are smaller in size than those in the north. 4) Different from the previous results, the northern part of North China and the Hetao area are combined into one climate region, and the Yangtze River is taken as the border between the Huanghuai region and Jiangnan region while the Yangtze River basin, especially its middle and lower reaches, is not regarded as one independent region. The names and geographic ranges of the 13 regions are displayed in Table 1. 


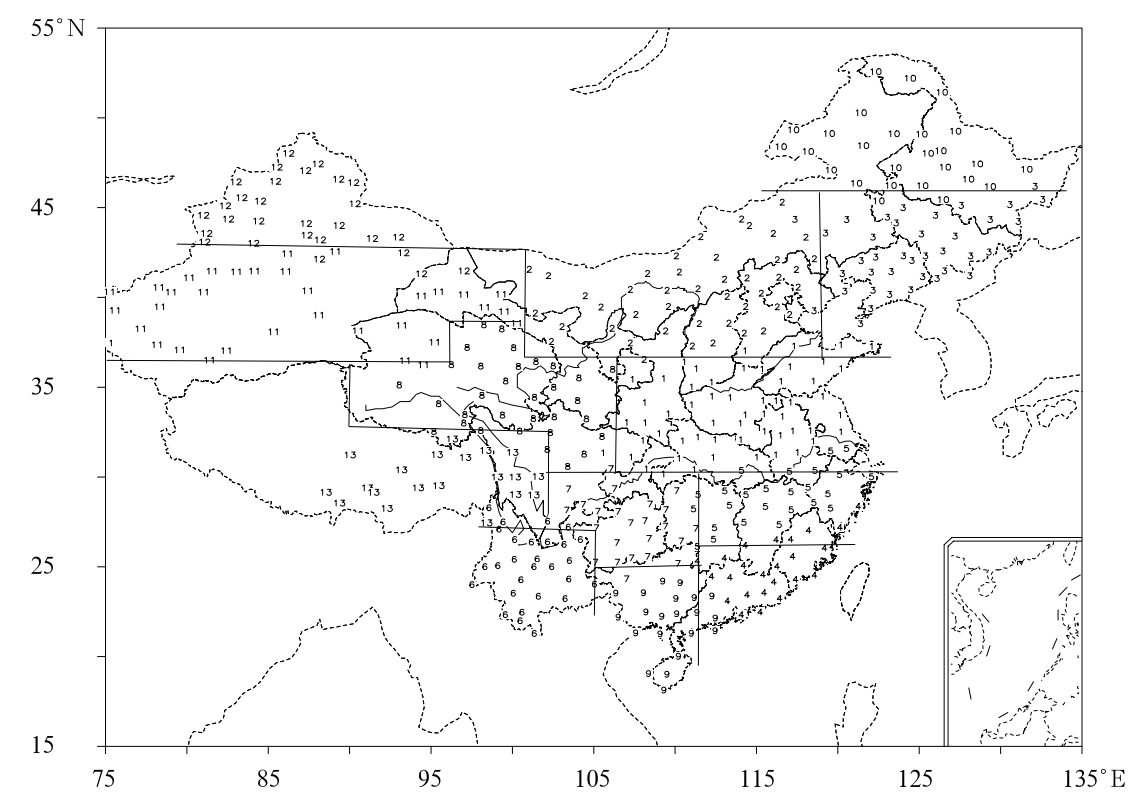

Fig. 1. Precipitation regimes in China (Chen et al., 2009).

Table 1. Details of the precipitation regimes (Chen et al., 2009)

\begin{tabular}{cll}
\hline No. & Name & \multicolumn{1}{c}{ Geographic range } \\
\hline 1 & Huanghuai region & $30^{\circ}-36.5^{\circ} \mathrm{N}, 105^{\circ}-122^{\circ} \mathrm{E}$ \\
2 & Hetao and North China & $36.5^{\circ}-46^{\circ} \mathrm{N}, 100^{\circ}-119^{\circ} \mathrm{E}$ \\
3 & Southern part of & $36.5^{\circ}-46^{\circ} \mathrm{N}, 119^{\circ}-133^{\circ} \mathrm{E}$ \\
& Northeast China & \\
4 & Southeastern coastal areas & $21^{\circ}-26.5^{\circ} \mathrm{N}, 112^{\circ}-120^{\circ} \mathrm{E}$ \\
5 & Jiangnan region & $26.5^{\circ}-30^{\circ} \mathrm{N}, 112^{\circ}-123^{\circ} \mathrm{E}$ \\
6 & Yunnan area & $21^{\circ}-27.5^{\circ} \mathrm{N}, 97.5^{\circ}-105^{\circ} \mathrm{E}$ \\
7 & Xianggui areas & $27.5^{\circ}-30^{\circ} \mathrm{N}, 102^{\circ}-105^{\circ} \mathrm{E}$ \\
& & $25^{\circ}-30^{\circ} \mathrm{N}, 105^{\circ}-112^{\circ} \mathrm{E}$ \\
8 & Qinghai area & $32.5^{\circ}-36.5^{\circ} \mathrm{N}, 90^{\circ}-105^{\circ} \mathrm{E}$ \\
& & $36.5^{\circ}-39^{\circ} \mathrm{N}, 96^{\circ}-100^{\circ} \mathrm{E}$ \\
& & $30^{\circ}-32.5^{\circ} \mathrm{N}, 102^{\circ}-105^{\circ} \mathrm{E}$ \\
9 & Guangxi area & $18^{\circ}-25^{\circ} \mathrm{N}, 105^{\circ}-112^{\circ} \mathrm{E}$ \\
10 & Northern part of & $46^{\circ}-53^{\circ} \mathrm{N}, 116^{\circ}-133^{\circ} \mathrm{E}$ \\
& Northeast China & \\
11 & Southern Xinjiang area & $36.5^{\circ}-43^{\circ} \mathrm{N}, 75^{\circ}-96^{\circ} \mathrm{E}$ \\
& & $39^{\circ}-43^{\circ} \mathrm{N}, 96^{\circ}-100^{\circ} \mathrm{E}$ \\
12 & Northern Xinjiang area & $43^{\circ}-48.5^{\circ} \mathrm{N}, 80^{\circ}-95^{\circ} \mathrm{E}$ \\
13 & Tibetan area & $27.5^{\circ}-32.5^{\circ} \mathrm{N}, 88^{\circ}-102^{\circ} \mathrm{E}$ \\
\hline
\end{tabular}

\section{Method and implementation}

As a transfer function, OSR (Wei, 2007) is used to establish the downscaling procedure for the RSPP. The selection of predictors is one of the key steps in the establishment of prediction models, especially for seasonal-scale climate prediction. It also affects the prediction accuracy to a great extent. Climate change contains seasonal, interannual, interdecadal, and even much longer-scale information. The predictors for elements on different timescales are significantly different. For the seasonal rainfall prediction, the critical predictors of the seasonal- to interannual-scale circulation systems have a more direct influence. Under the background of global warming and for the purpose of avoiding the effect of the long-term variation on the selection of predictors, in this paper, we use a simple linear regression to eliminate long-term trends in the precipitation data, the dynamic model outputs, and the reanalysis data. The three types of data are separately detrended and their anomaly correlation coefficients (ACCs) are calculated. Meanwhile, the highskill area is being searched for. It is actually an area where the model successfully predicts the large-scale atmospheric circulation elements that are closely related to the regional precipitation. Then, we take the representative model data at the grids within the highskill area as predictors, assemble the predictor sets, establish the downscaling prediction models through the OSR, and finally carry out the RSPP in different regions of China. Subsequently, the long-term variation tendency is added back to the prediction results and the final prediction products are obtained. Actually, 
a similar approach has been used in the monthly climate prediction, and high prediction skills have been achieved ( $\mathrm{Gu}$ et al., 2009).

Specifically, the least square method is used in this paper to remove the long-term variation trends of seasonal mean precipitation, model outputs, and NCEP/NCAR reanalysis data in each region. ACCs are calculated by using the detrended data including the regional summer precipitation anomalies, geopotential height fields at 200, 500, and $700 \mathrm{hPa}$, zonal and meridional wind fields at 200 and $850 \mathrm{hPa}$, as well as sea level pressure field from the model outputs in the same season. After that, other ACCs are obtained by using regional summer precipitation anomalies and the corresponding fields from the NCEP/NCAR reanalysis data in the same period. Then, we combine the distribution fields of ACCs between seasonal mean precipitation anomalies and model output fields with those between seasonal mean precipitation anomalies and NCEP/NCAR reanalysis fields, and find the overlapping regions where the two sets of ACCs have the same sign and meanwhile reach the 0.05 significance level. The overlapping area size should be larger than $4 \times 4$ grids. If the area is too small, it is not considered as a region for key predictors. After sorting out the representative grids of the critical areas that fit the above conditions, the predictor sets can be accordingly selected and the prediction models are established by the OSR method. If too many predictors are selected, e.g., more than 10 , the predictors out of each field will be sorted by their correlation coeffcient values and determined as the representative predictor only for the area with the largest correlation coefficient. Thus, the number of all the predictors of each region is confined to less than 10. The final precipitation prediction can be expressed as:

$$
R_{p}=R_{t}+R_{v}
$$

where $R_{p}$ is the final precipitation prediction value, $R_{t}$ is the linear trend of precipitation while $R_{v}$ is the prediction that reflects the annual variability of precipitation calculated from the regional prediction model. If $R_{t}>R_{v}$, it means that the contribution of decadal signals is greater than that of interannual signals, and vice versa.

\section{Results and cross-validation}

\subsection{Verification and cross-validation}

To verify the downscaled prediction accuracy and assess the prediction skill for summer precipitation anomalies in each region from 1983 to 2006, one-year out cross-validation tests (Barnston and He, 1996; Wu and $\mathrm{Wu}, 2005)$ are conducted. The detailed procedure is as follows: 1) the prediction equation is established by eliminating the $M$ th-year data from all the available data; 2 ) the predictor in the $M$ th year is taken to make prediction whereas the predictand in the $M$ th year is taken as observations. The above procedure is repeated until $M$ takes all the possible values, thus the prediction value series along with the observation data series are obtained. The prediction skills of the whole model system are assessed by comparing the consistency rate of the positive and negative tendencies and the ACCs of the two series. The $M$ th-year data are not used to establish model equations, so the sample test is independent.

We have established the RSPP equations by removing the data of the prediction year, conducted the predictions year by year, and then compared the results with CGCM/NCC outputs since 1983. When selecting predictors, we find no suitable predictors for Xianggui areas because of their special climate features and the limited prediction skill of the CGCM/NCC, so here we mainly analyze prediction results of the other 12 areas. Comparing the summer predictions each year through cross-validation tests with observations in different areas (Fig. 2), we find that most RSPPs are close to observations with consistent and coherent anomaly percentage signs, suggesting that the predicted distribution of drought and flood is generally reasonable. The skill of the downscaled RSPPs is higher than that of CGCM/NCC outputs. In order to compare the downscaled RSPPs with observations quantitatively, we calculate the correlation coefficient between the cross-validation tests and the observation data in relevant areas (Table 2). The ACCs in all areas but Yunnan and North China are 

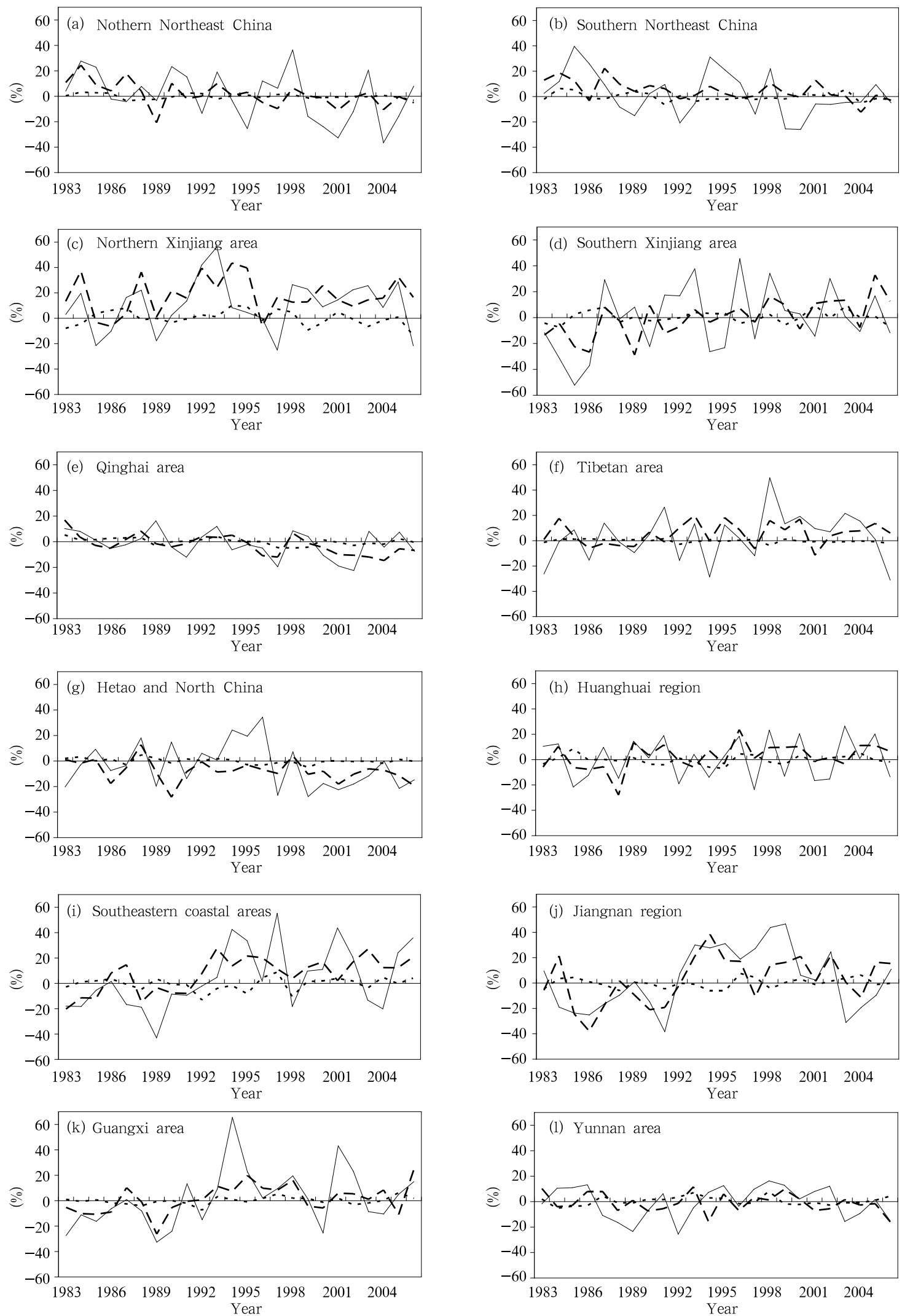

Fig. 2. Comparison of downscaled RSPPs (dashed line), model outputs (dotted line), and observations (real line) of summer precipitation percentage anomalies $(\%)$ in each region. 
Table 2. The correlation coefficient of summer precipitation anomalies between RSPPs and observations in each region based on 24-yr sample data

\begin{tabular}{|c|c|c|c|c|c|c|c|c|c|c|c|c|}
\hline Region & $\begin{array}{c}\text { Northern } \\
\text { Northeast } \\
\text { China }\end{array}$ & $\begin{array}{c}\text { Southern } \\
\text { Northeast } \\
\text { China }\end{array}$ & $\begin{array}{c}\text { Northern } \\
\text { Xinjiang } \\
\text { area }\end{array}$ & $\begin{array}{c}\text { Southern } \\
\text { Xinjiang } \\
\text { area }\end{array}$ & $\begin{array}{c}\text { Qinghai } \\
\text { area }\end{array}$ & $\begin{array}{c}\text { Tibetan } \\
\text { area }\end{array}$ & $\begin{array}{l}\text { Hetao } \\
\text { and } \\
\text { North } \\
\text { China }\end{array}$ & $\begin{array}{l}\text { Huang- } \\
\text { huai } \\
\text { region }\end{array}$ & $\begin{array}{l}\text { South- } \\
\text { eastern } \\
\text { coastal } \\
\text { areas }\end{array}$ & $\begin{array}{c}\text { Jiangnan } \\
\text { region }\end{array}$ & $\begin{array}{c}\text { Yunnan } \\
\text { area }\end{array}$ & $\begin{array}{c}\text { Guangxi } \\
\text { area }\end{array}$ \\
\hline $\mathrm{ACC}$ & 0.49 & 0.34 & 0.45 & 0.45 & 0.54 & 0.36 & 0.29 & 0.43 & 0.45 & 0.64 & 0.13 & 0.60 \\
\hline
\end{tabular}

greater than 0.3 , of which the Jiangnan region is up to 0.64 .

The consistency of the anomaly percentage signs between downscaled predictions and observations shows that 8 out of the 12 regions in 16 or more years out of the 24 years (1983-2006) have the same anomaly percentage sign, with the prediction accuracy of drought and flood trends exceeding $67 \%$. The eight areas include northern Xinjiang, southern Xinjiang, Qinghai, Tibet, Hetao and North China, southeastern coastal areas, Jiangnan, and Guangxi. Among them, four areas, i.e., northern Xinjiang, Hetao and North China, southeastern coastal areas, and Guangxi, share the same coherent anomaly signs for $18 \mathrm{yr}$ with the prediction accuracy of $75 \%$ while northern Xinjiang has correctly predicted for $20 \mathrm{yr}$ and the accuracy is up to $83 \%$. Comparison of the cross-validation tests and observation data indicates that this method is applicable and the prediction accuracy is high and stable in most areas. In general, the summer climate predictions for the above eight areas and the Huanghuai region are relatively better.

\subsection{Analysis of the prediction skill}

Using the consistency rate of anomaly percentage signs, the prediction accuracy of downscaled RSPPs in the 12 regions is analyzed year by year and compared with that of CGCM/NCC direct outputs (Fig. 3 ). The results show that the consistency rates of the directly predicted regional rainfall anomaly and the observed rainfall percentage sign in the same region maintain around only $50 \%$, and even as low as $20 \%$ in some years. This means that the prediction results of the CGCM/NCC model are not desirable. After using the downscaling method, the rates of correct prediction rise up to $70 \%$, and even to $90 \%$ in 5 of the 24 years. Therefore, the results of the downscaled prediction are superior to the outputs of the CGCM/NCC.
In order to assess the predictability of the RSPP, the ACCs of both the model predictions and the downscaled RSPPs with the observations are compared. We find from Fig. 4 that the downscaled RSPP improves the prediction skill remarkably and the pattern of its skill closely follows that of the skill of the model outputs. The areas with relatively high correlation coefficients between model outputs and observations also show higher correlation coefficients between downscaled regional prediction results and observations.

\subsection{Causes of the high-skill predictions}

The predictability in different regions is quite different. Here we choose two representative regions, Jiangnan and Yunnan, to explain the reasons for the difference. The prediction skill is high in Jiangnan but low in Yunnan. The Jiangnan region refers to the rectangle area $26.5^{\circ}-30^{\circ} \mathrm{N}, 112^{\circ}-123^{\circ} \mathrm{E}$ (Table 1 ), which is a bit larger than the size defined by Chen Shaodong et al. (2003). Based on the previous studies, the climate features in Jiangnan is not only distinguished from those over the middle and lower reaches of the Yangtze River (Wang et al., 1999), but also different from those in South China (Deng and Wang, 2002), thus it is worthwhile to analyze its seasonal climate prediction results separately.

There are six predictors for the Jiangnan region, including the geopotential height fields at 200 and 500 $\mathrm{hPa}$ as well as the zonal and meridional wind fields at 850 and $200 \mathrm{hPa}$. Using OSR as the transfer function, we compared all types of grouped prediction results, and only adopted high-correlation factors in the geopotential height fields at 200 and $500 \mathrm{hPa}$ along with the factors in the meridional wind field at 850 $\mathrm{hPa}$ to establish the prediction equation.

$$
y=2.056+0.139 x_{1}+0.268 x_{2}+172.43 x_{3},
$$




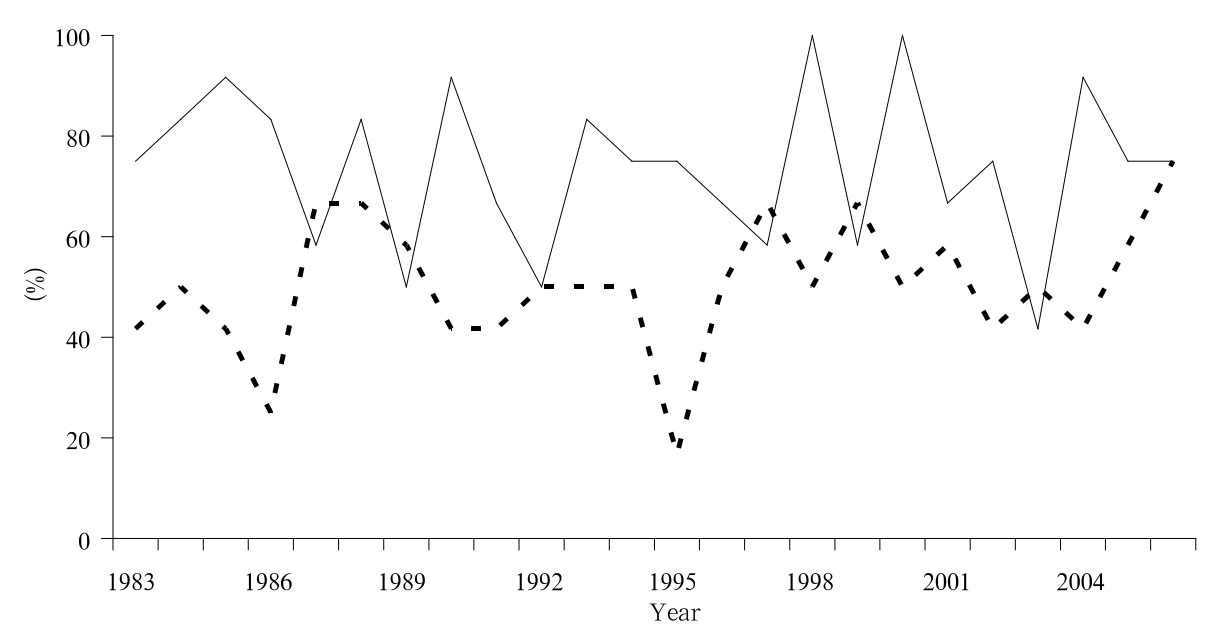

Fig. 3. The skills of downscaled RSPPs (real line) and model outputs (dotted line) of precipitation anomalies during 1983-2006. Vertical axis shows the ratio (\%) of the consistency of regional precipitation anomaly signs between predictions and observations for all the 12 regions in each year.

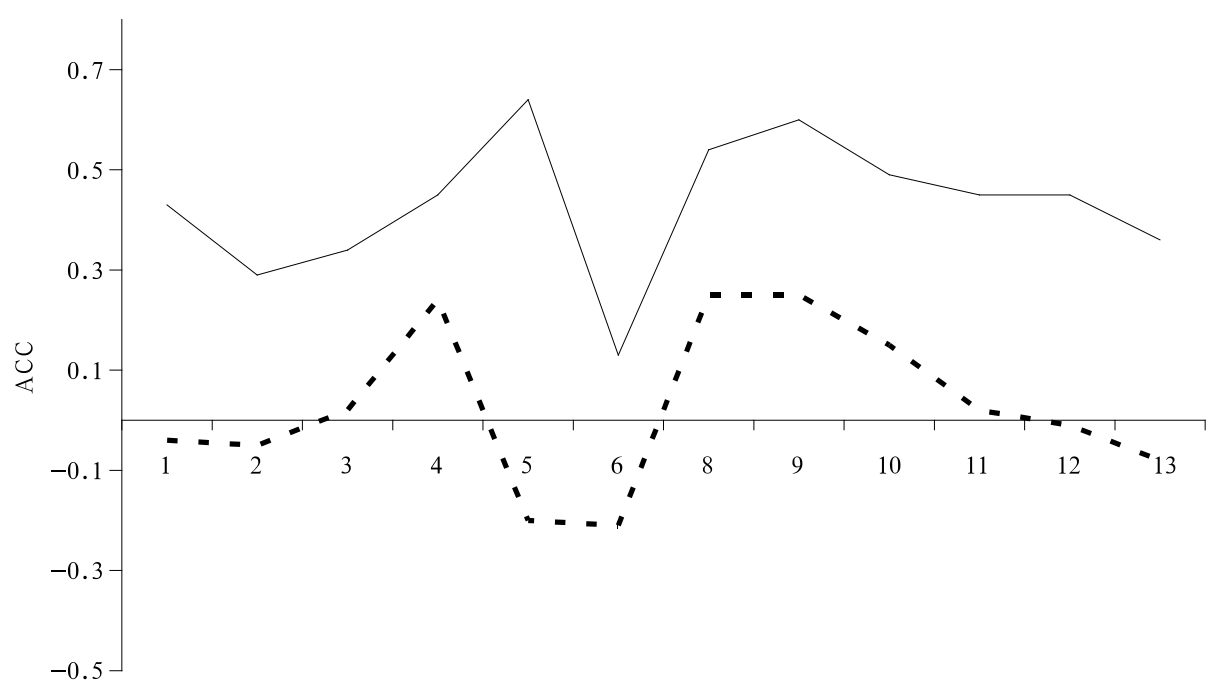

Fig. 4. ACCs of the observation with downscaled RSPPs (real line), and with CGCM/NCC outputs (dotted line) for 12 regions in summer. The regions are denoted by numbers (see Table 1) along the $x$ axis.

where $x_{1}, x_{2}$, and $x_{3}$ are predictors selected from 200-, 500 -hPa geopotential height fields and 850-hPa meridional wind fields.

By analyzing the factors used in the equation, we find that the independence of the three predictors is good (Table 3). The correlation coefficient is -0.22 between the first and second predictor, 0.17 between the first and third predictor, and -0.15 between the second and third predictor. Good independence between the predictors is important for establishing the statistical regional climate prediction models during the downscaling process.

Table 3. The correlation coefficient between every two predictors for the Jiangnan region

\begin{tabular}{cccc}
\hline $\begin{array}{c}\text { Correlation } \\
\text { coefficient }\end{array}$ & $x_{1}(\mathrm{H} 200)$ & $x_{2}(\mathrm{H} 500)$ & $x_{3}$ (V850) \\
\hline$x_{1}(\mathrm{H} 200)$ & 1 & -0.22 & 0.17 \\
$x_{2}(\mathrm{H} 500)$ & & 1 & -0.15 \\
$x_{3}(\mathrm{~V} 850)$ & & & 1 \\
\hline
\end{tabular}

Four predictors are chosen for the Yunnan area from the geopotential fields at 200 and $500 \mathrm{hPa}$ and 
the zonal and meridional wind fields at $200 \mathrm{hPa}$. When the prediction equation is established with the OSR, only the first factor is used after a comparison among various predictions. Similarly, by analyzing the relations of the four predictors, we find their ACCs are high. The correlation coefficient is 0.96 between the first and second predictor, 0.72 between the first and third, -0.7 between the first and fourth, 0.71 between the second and third, -0.69 between the second and fourth, and -0.5 between the third and fourth preditor. No good independence exists between any two factors, so only the first factor is adopted to establish the prediction model. No independence between any two predictors may lead to poor prediction skills.

Based on the above analysis, we realize that the chosen predictor plays a key role in utilizing the transfer function to build the downscaling RSPP. To find good predictors is the focus of this paper. By combining the observation data with model hindcast data and calculating ACCs twice, we identified good predictors that represent not only the key factors influencing the regional predictand but also the high-skill elements in the CGCM/NCC output. The next two questions are 1) whether the predictor found this way is applicable, and 2) how to explain the high predictability. A detailed analysis of the rainfall prediction in the Jiangnan region is given below.

As shown with the red square in Fig. 5a, the predictor from the geopotential field at $200 \mathrm{hPa}$ lies over the West Pacific $\left(15^{\circ}-20^{\circ} \mathrm{N}, 125^{\circ}-150^{\circ} \mathrm{E}\right)$. The precipitation in the Jiangnan region has a negative correlation with the $200-\mathrm{hPa}$ geopotential height in this region. When the geopotential field over this region is higher than normal, the rainfall in Jiangnan is less, and vice versa. This predictor reflects the effect of the subtropical circulation on the precipitation anomaly in the Jiangnan region of China.

The predictor from the geopotential field at 500 $\mathrm{hPa}$ lies above the Bering Strait, as marked in Fig. 5b. Figure 5b shows that the abnormal general circulation over the mid and high latitudes has an effect on precipitaton in the Jiangnan region, as indicated by the negative correlation between the 500-hPa geopotential height over the Bering Strait and the Jiangnan precipitation. When the geopotential height is higher than normal, the precipitation in Jiangnan is less, and vice versa. The observed geopotential height field to the east of Japan and south to this predictor area is positively correlated with the observed precipitation in Jiangnan but the northwestern Pacific region has a negative correlation with Jiangnan regional rainfall, so there appears a teleconnection wave-like pattern of "-+-".

The predictor chosen from the 850 -hPa meridional wind field is found over the northeast of the Japan Sea, as seen in Fig. 5c. Obviously, the Jiangnan regional precipitation has a positive correlation with the 850 -hPa meridional wind in this region. When the wind in this region is stronger than normal, the rainfall in Jiangnan is more than normal too, and vice versa.

To analyze the causes of the abnormal precipitation in the Jiangnan region, we define the years with summer precipitation anomaly percentage exceeding $20 \%$ as wet years, e.g., 1993, 1994, 1995, 1998, 1999, and 2002; and the years with precipitation anomaly percentage lower than $-20 \%$ as dry years, e.g., 1985, 1986, 1991, and 2003. By using the NCEP/NCAR reanalysis data to derive the geopotential height difference between wet and dry years, the atmospheric circulation features over the Jiangnan region are studied next.

Figure 6a displays the geopotential height difference at $200 \mathrm{hPa}$ between wet and dry years. Negative anomalies appear over the large Asian continent to the south of $40^{\circ} \mathrm{N}$, and this is the region for selecting the predictor when establishing the prediction equation for the Jiangnan region. The geopotential height field over the mid and high latitudes of Asia exhibits strong positive anomalies and is controlled by the ridge of the subtropical high. The South Asian High $(\mathrm{SAH})$ is weaker than normal and westward to its normal position. Such an atmospheric circulation pattern is favorable for the southward moving of cold fronts, resulting in more precipitation across the Jiangnan region. This is in agreement with the relationship between the Jiangsu Meiyu and SAH proposed by Liu et al. (2008).

Figure $6 \mathrm{~b}$ shows the distribution of geopotential 
height difference at $500 \mathrm{hPa}$ in the summer period between wet and dry years. Over the Bering Strait, negative anomalies occur. In terms of the ACC in Fig. 5, the Jiangnan regional precipitation is negatively correlated with the geopotential height over the Bering Strait, so the difference field corresponds to the ACC
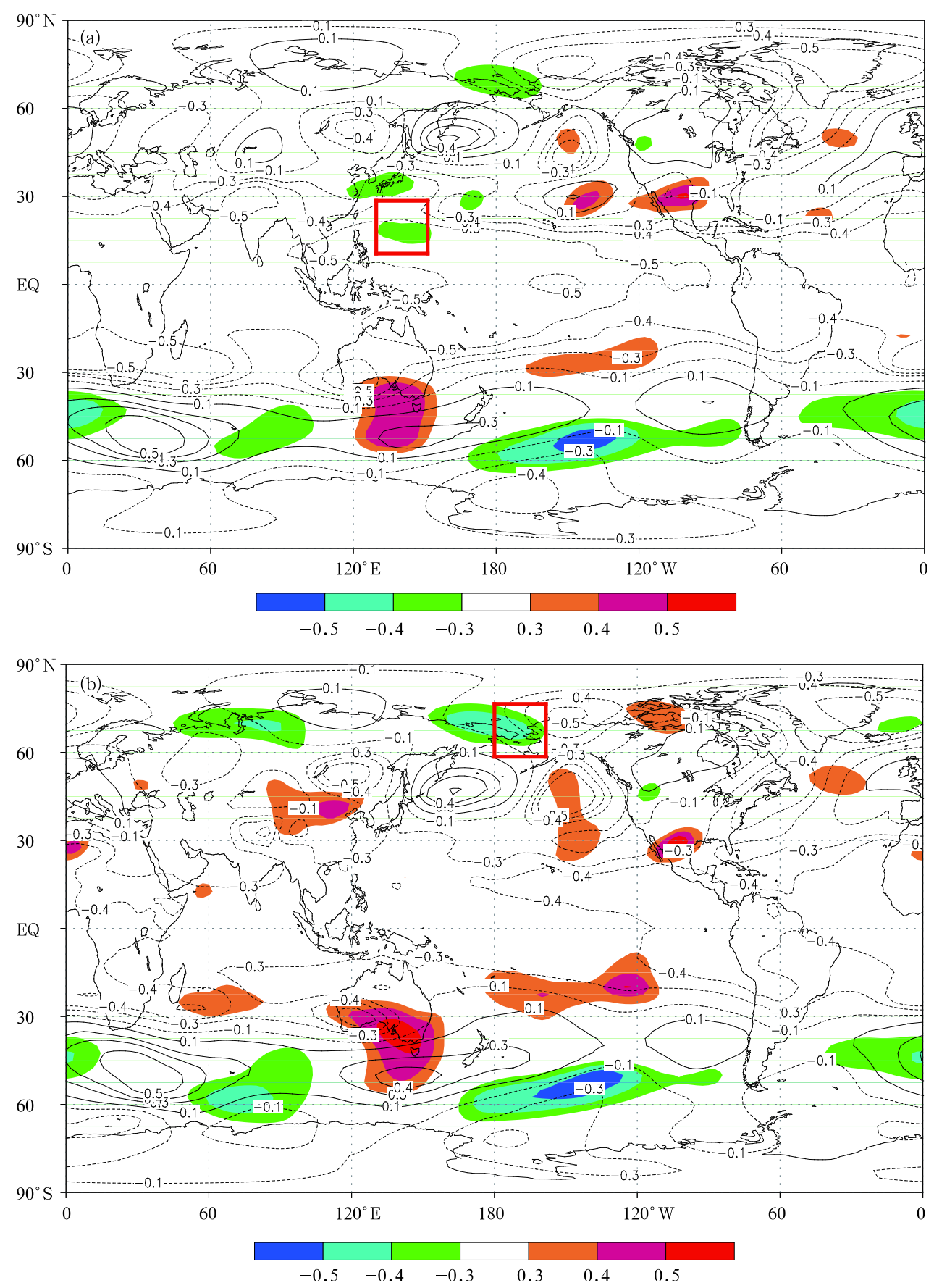

Fig. 5. Correlations between summer precipitation over the Jiangnan region, NCEP/NCAR reanalysis data, and CGCM/NCC outputs of geopotential height at $200 \mathrm{hPa}$ (a) and $500 \mathrm{hPa}$ (b), and 850-hPa wind field (c) over the globe from 1983 to 2006. Contours indicate the ACC between the Jiangnan summer rainfall and NCEP/NCAR reanalysis data, and the solid contours indicate positive correlation while dashed contours mean negative correlation. Shadings depict the area where the ACC between the Jiangnan summer rainfall and the model output reaches 0.3 or -0.3 with the warm color denoting positive correlation and the cool color negative correlation. 


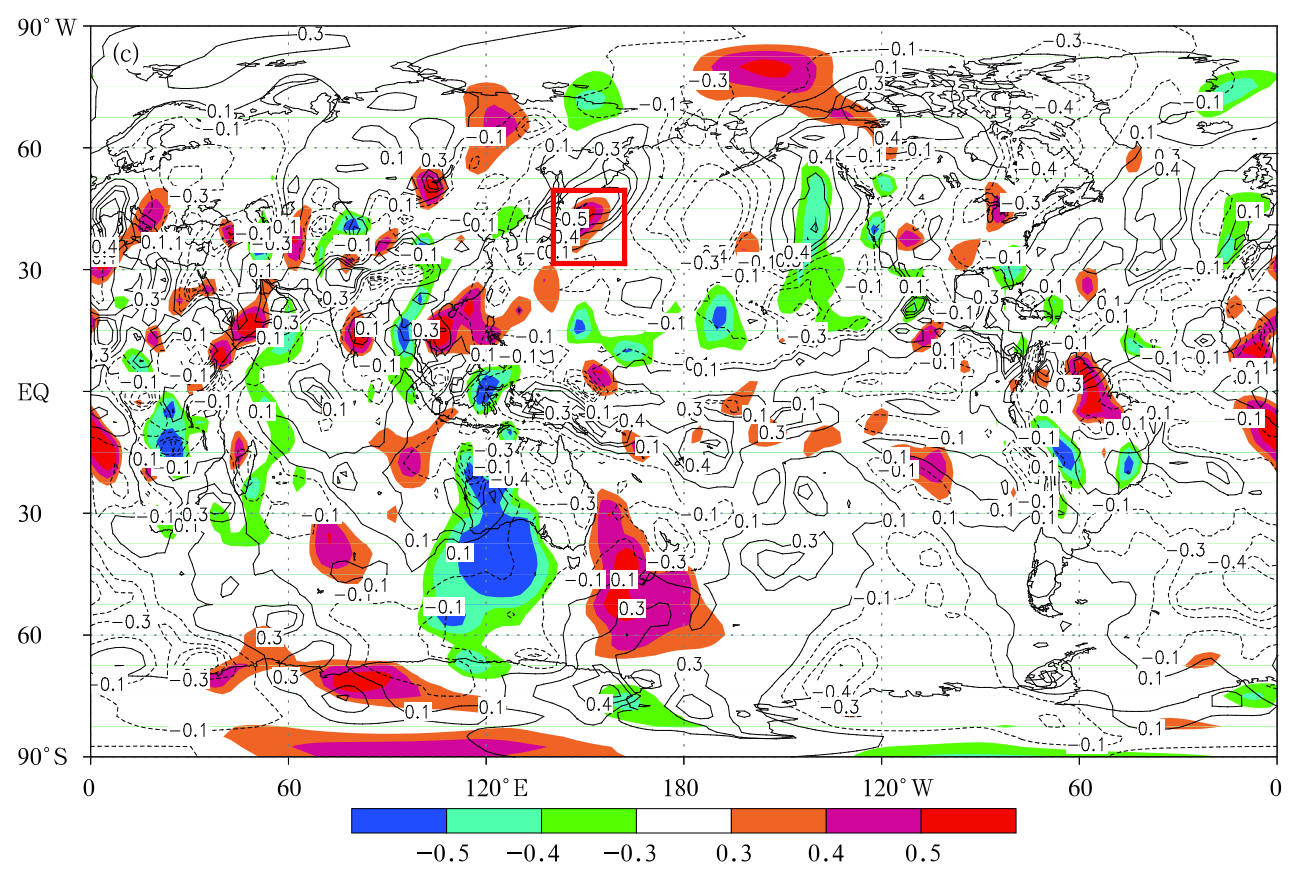

Fig. 5. (Continued.)

field shown in Fig. 5b. Why can the abnormal geopotential height over the Bering Strait significantly impact the precipitation of the Jiangnan region? A wavelike pattern of "-+-" from the Bering Strait to Northwest Pacific is identified, so the abnormal height field over the Bering Sea is likely to propagate to affect the Jiangnan precipitation, but the detailed mechanism needs to be further explored.

The 850-hPa wind difference between wet and dry years is shown in Fig. 6c. There is an anticyclone circulation in the area to the east of the South China Sea and the Philippines. The southerly flow in the west of the anticyclone moves offshore along the Northwest Pacific and the area to the east of Japan, then shifts around $45^{\circ}-50^{\circ} \mathrm{N}$ and joins the southerly flow from the westerlies in the northeast of China. Afterwards, it travels southward to North China, Shandong Province, Jianghuai region, etc., forming a cyclonic return flow. Then, over the Jiangnan region, the north wind anomaly confronts the southwest flow from the low latitudes, producing the wind shear, which leads to more precipitation in the Jiangnan region. During the process, southerly wind blows in the northeastern part of Japan, which is exactly the region for selecting the predictor of the $850-\mathrm{hPa}$ meridional wind in the establishment of the prediction model. The precipitation in the Jiangnan region is positively correlated with the meridional wind in this area. The stronger the meridional wind in the area to the east of Japan Sea, the stronger the southwesterly wind around the area to the east of Japan, and the more intense the air flow down to the southwest over the northeast region of China, and then the more easily the wind shear is formed, leading to more precipitation in the Jiangnan region in the end.

The above analyses have revealed the physical mechanisms for the precipitation anomalies over the Jiangnan region of China, i.e., the low-level anticyclonic circulation dominates the Northwest Pacific while the western Pacific subtropical high is quite strong; meanwhile, the cold fronts in North China are very active, and there are significant anomalous convergence at the low level ( $850 \mathrm{hPa})$ over the Jiangnan region but obvious divergence at the high level (200 $\mathrm{hPa}$ ). All these factors are favorable for generation of excessive rainfall in the Jiangnan region. Here, the reason why the downscaled RSPP has higher skills for precipitation prediction in the Jiangnan region lies in the fact that the selected predictors have good physical significance. Although the CGCM/NCC has limited 

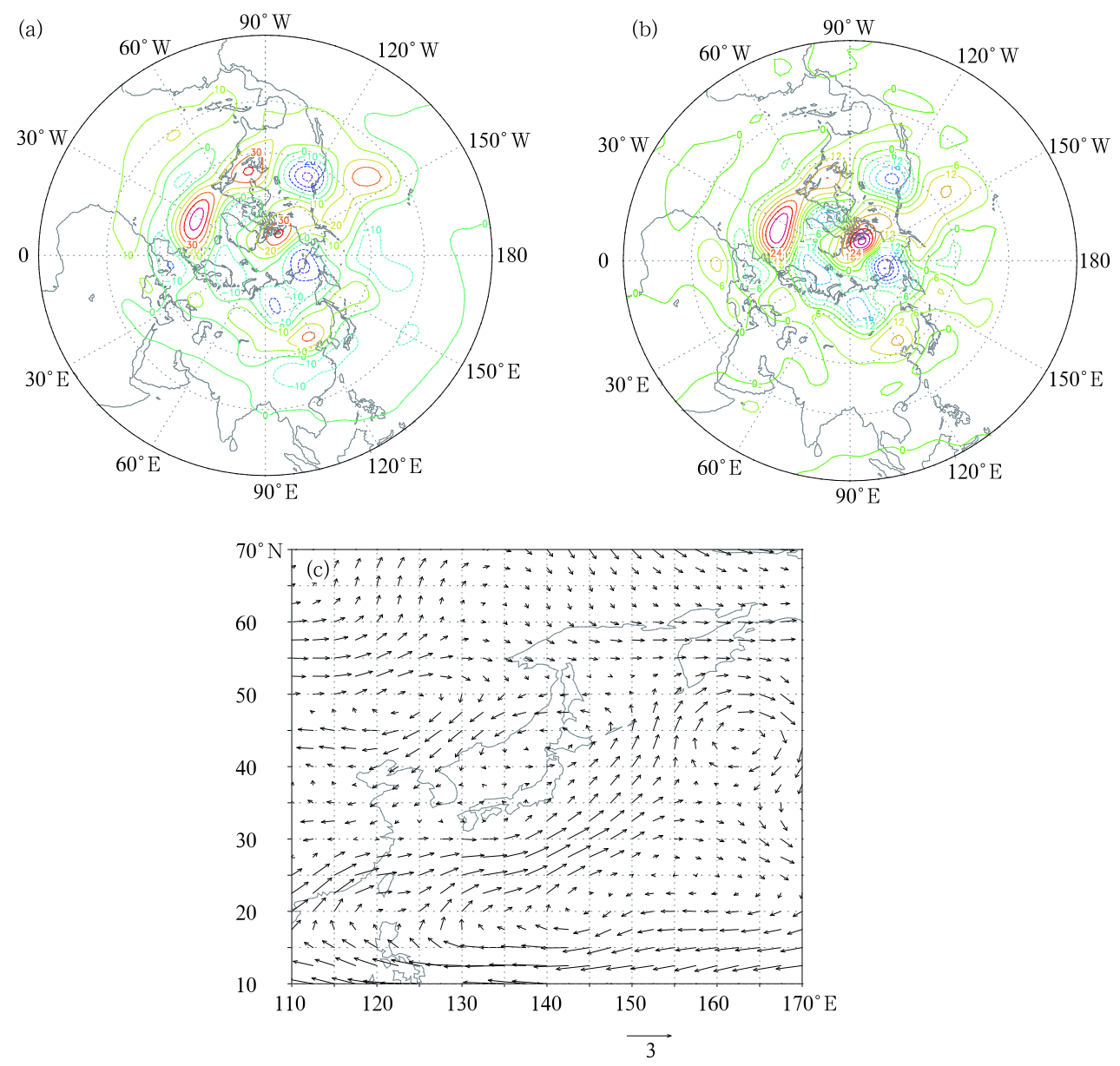

Fig. 6. Distributions of the difference of (a) 200-hPa geopotential height, (b) 500-hPa geopotential height, and (c) $850-\mathrm{hPa}$ wind field between the wet and dry summer years in the Jiangnan region.

ability in providing the optimal prediction for the whole circulation system, it does better in predicting some features of the atmospheric circulation. There exist representative areas for selecting useful predictors at 850,500 , and $200 \mathrm{hPa}$, which offers a good basis for the downscaled RSPP.

\section{Conclusions}

In accordance with China's precipitation regionalization, a downscaling method is developed and used in the RSPP in China based on the precipitation observations, the CGCM/NCC model products, and the NCEP/NCAR reanalysis data. Optimal predictors have been identified by two iterative calculations of ACC. The causes for high- and low-skill predictions in representative regions are analyzed. The results are summarized as follows:

(1) The long-term tendency in the model data, reanalysis data, and observation data is removed before calculating the ACC so as to avoid the influence of the long-term trend of the data and to improve the accuracy of the interannual rainfall prediction.

(2) The optimal predictors are selected through calculation of anomaly correlation coefficients (ACCs) twice to ensure that the high-skill areas of the CGCM/NCC are also those of observations, with the ACC value reaching the 0.05 significant level. The selected predictors are of physical significance, favorable for improving the prediction accuracy.

(3) The dependence between the predictors affects the prediction accuracy to a large degree in the shortterm climate prediction. Therefore, routine operations of climate prediction require to choose the predictors 
with real physical significance and to use independent predictors when establishing the downscaling procedure for the RSPP.

(4) The downscaling method based on the highskill outputs of the CGCM/NCC can greatly improve the accuracy of the RSPP, and the performance of the RSPP depends significantly on the skill of the model used.

It is clear that the skill of the RSPP depends essentially on the model performance. Therefore, improving the performance of the dynamic climate model and reducing the model's systematic bias are important for improving the climate predictability. At the same time, the physical mechanism that affects regional precipitation should be further investigated. In addition, diagnostic analysis of historical data needs to be carried out in combination with extraction of the high-skill information from the model outputs in order to improve the accuracy of the seasonal climate prediction.

\section{REFERENCES}

Ai Wanxiu, Dong Wenjie, and Zhang Peiqun, 2008: A downscaling method based on the empirical orthogonal function and its application in seasonal prediction. J. Tropical Meteor., 24(4), 320-326. (in Chinese)

Barnston, A. G., and Y. He, 1996: Skill of CCA forecasts of 3-month mean surface climate in Hawaii and Alaska. J. Climate, 9(10), 2579-2605.

Chen Deliang, 2000: A monthly circulation climatology for Sweden and its application to a winter temperature case study. Int. J. Climatol., 20, 1067-1076.

— and Chen Youmin, 2003: Association between winter temperature in China and upper air circulation over East Asia revealed by Canonical Correlation Analysis. Global and Planetary Change, 37, 315-325.

Chen Lijuan, 2008: Predictability analysis of the seasonal climate and the downscaling applications based on the coupled atmosphere-ocean model. Ph. D. thesis, Institute of Atmospheric Physics, Chinese Academy of Sciences. (in Chinese)

—, Li Weijing, Zhang Peiqun, et al., 2003: Application of a new downscaling model to monthly preciptation forecast. J. Appl. Meteor. Sci., 16, 56-62. (in Chinese)
—, Chen Deliang, Wang Huijun, et al., 2009: Regionalization of precipitation regimes in China. Atmos. Oceanic Sci. Lett., 2, 301-307.

Chen Lieting and Wu Rongguang, 1994: Climatic division of precipitation in eastern China and drought-flood variation in various regions. Chinese J. Atmos. Sci., 18, 586-595. (in Chinese)

Chen Shaodong, Wang Qianqian, and Qian Yongfu, 2003: Preliminary discussions of basic climatic characteristics of precipitation during raining seasons in regions south of Yangtze River and its relationship to SST anomalies. J. Tropical Meteor., 19, 260-268. (in Chinese)

Deng Liping and Wang Qianqian, 2002: On the relationship between precipitation anomalies in the 1st raining season (April-June) in southern China and SST offshore waters in China. J. Tropical Meteor., 18, 45-55. (in Chinese)

Ding Yihui, Li Qingquan, Li Weijing, et al., 2004: Advance in seasonal dynamical prediction operation in China. Acta Meteor. Sinica, 62(5), 598-612. (in Chinese)

Fuentes, U., and D. Heimann, 1996: Verification of statistical dynamical downscaling in the Alpine region. Climate Research, 7, 151-168.

Goddard, L., S. J. Mason, S. E. Zebiak, et al., 2001: Current approaches to seasonal-to-interannual climate predictions. Int. J. Climatol., 21, 1111-1152.

Gu Weizong, Chen Lijuan, Zhang Peiqun, et al., 2009: Downscaling precipitation prediction in China based on optimization information extracted from monthly dynamic extended range forecast. Acta Meteor. Sinica, 67(2), 280-287. (in Chinese)

Hellstrøm, C., and D. Chen, 2003: Statistical downscaling based on dynamically downscaled predictors: Application to monthly precipitation in Sweden. Adv. Atmos. Sci., 20, 951-958.

Kalney, E., M. Kanamitsu, R. Kistler, et al., 1996: The NCEP/NCAR 40-yr reanalysis project. Bull. Amer. Meteor. Soc., 77, 437-471.

Li Qingquan, Ding Yihui, and Zhang Peiqun, 2004: Primary verification and assessment on the extra-seasonally predictive capability of a Global Atmospheric-Ocean Coupled Model in the raining season. Acta Meteor. Sinica, 62(6), 740-751. (in Chinese)

Li Weijing and Chen Lijuan, 1999: Research on reexplanation and reanalysis method of dynamical extended range forecast products. Acta Meteor. Sinica, $\mathbf{5 7}(3)$, 338-345. (in Chinese) 
—, Zhang Peiqun, Li Qingquan, et al., 2005: Research and operational application of dynamical climate model prediction system. J. Appl. Meteor. Sci., 16(Suppl.), 1-11. (in Chinese)

Liu Mei, Hu Luolin, Zhang Bei, et al., 2008: Study on connection between South Asian high characteristics of $100 \mathrm{hPa}$ in Plum Flood Season and Jiangsu Plum Rain. J. Tropical Meteor., 24(3), 284-293. (in Chinese)

Qin Aimin and Qian Weihong, 2006: The seasonal climate division and precipitation trends of China in recent 41 years. Plateau Meteor., 25, 495-502. (in Chinese)

Ren Hongli, Zhang Peiqun, Chou Jifan, et al., 2006: Large-scale low-frequency rainfall regimes and their transition modes in summertime over China. Chinese Sci. Bull., 51(11), 1355-1367.

Sun Linhai, Zhao Zhenguo, Xu Li, et al., 2005: Study of summer rain pattern in monsoon region of East China and its circulation cause. J. Appl. Meteor. Sci., 16, 56-62. (in Chinese)

Wang Shaowu, Ye Jinlin, Gong Daoyi, et al., 1998: Study on the pattern of summer rainfall in eastern China.
J. Appl. Meteor. Sci., 9(Suppl.), 65-74. (in Chinese)

Wang Yehong, Wang Qianqian, and Zhao Yuchun, 1999: Characteristics of precipitation anormaly over the middle lower reaches of the Yangtze River related to precipitation and temperature anomalies of China. J. Nanjing Meteor. Institute, 22, 685-691. (in Chinese)

Wei Fengying, 2007: Climate Statistic, Diagnostic and Prediction Methods (Version 2). China Meteorological Press, Beijing, 220-226. (in Chinese)

Wilby, R. L., and T. M. Wigley, 1997: Downscaling general circulation model output: A review of methods and limitations. Progress in Physical Geography, 21, $530-548$.

Wu Hongbao and Wu Lei, 2005: Methods for Diagnosis and Prediction of Climate Variation Rates. China Meteorological Press, Beijing, 131-145. (in Chinese)

Zhang Liping, Ding Yihui, Li Qingquan, et al., 2005: An approach and its test to improve simulated summer rainfall fields of National Climate Center coupled ocean atmosphere model. Climatic and Environmental Research, 10(2), 209-219. (in Chinese) 